\title{
FICÇÃO, HISTÓRIA E REPRESENTAÇÃO: O NEGRO NA TELENOVELA LADO A LADO
}

\author{
FICTION, HISTORY AND REPRESENTATION: THE AFRICAN-BRASILIAN \\ IN THE SOAP OPERA LADO A LADO
}

\author{
FICCIÓN, HISTORIA Y REPRESENTACIÓN: EL NEGRO EN LA \\ TELENOVELA LADO A LADO
}

\author{
Marinês Andrea Kunz \\ Docente do Mestrado em \\ Processos e Manifestações Culturais e do curso de Letras \\ Universidade Feevale \\ marinesak@feevale.br \\ Magna Lima Magalhães \\ Docente do Mestrado em \\ Processos e Manifestações Culturais e do curso de História \\ Universidade Feevale \\ magna@ feevale.br \\ Cláudia Santos Duarte \\ Tutora das disciplinas das Ciências Humanas no Núcleo de Tutorias EaD \\ Universidade Feevale \\ claudiasa@feevale.br
}

\section{Resumo}

O estudo da relação entre a ficção e a História a partir da representação do negro na telenovela Lado a Lado, veiculada pela Rede Globo de Televisão, objetiva identificar e discutir as características da abordagem feita pela obra, levando em consideração a recorrente ausência da temática referente aos negros na teledramaturgia nacional. A relevância desta análise está no significativo papel desse tipo de produção na difusão de diferentes discursos a respeito da nação. O enfoque proposto tem como marco teórico os estudos de Joel Zito Araújo (2004), Linda Hutcheon (1991), Sandra Pesavento (2008), Paul Ricoeur (1997) e Roger Chartier (1990). Considerando que a telenovela ocupa um lugar de destaque como produto cultural no Brasil, Lado a Lado trouxe importantes contribuições acerca da história do negro brasileiro no pós-abolição.

Palavras-chave: Lado a Lado. Ficção e História. Representação do negro.

\begin{abstract}
The study of the relation between fiction and history from the Afro-Brazilian representation in the soap opera Lado a Lado (meaning Side by Side), broadcast by Globo Television Network, aims to identify and discuss the features of the approach used for the production, taking into account the recurrent absence of themes related to blacks on Brazil's television drama. The relevance of this analysis is the significant role of this type of production in the diffusion of
\end{abstract}


different discourses on the nation. The proposed approach has as theoretical basis the studies of Joel Zito Araújo (2004), Linda Hutcheon (1991), Sandra Pesavento (2008), Paul Ricoeur (1997) and Roger Chartier (1990). Considering that soap operas occupy a prominent place as a cultural product in Brazil, Lado a Lado brought important contributions on the history of post- abolition Afro-Brazilian population.

Keywords: Lado a Lado. Fiction and History. Afro-Brazilian representation.

\section{Resumen}

El estudio de la relación entre la ficción y la historia de la representación negro en la telenovela de Lado a Lado, transmitido por Red Globo de Televisión, tiene como objetivo identificar y discutir el enfoque de características hechas por el trabajo, teniendo en cuenta la ausencia del temas relacionados con negro en drama de la televisión nacional. La relevancia de este análisis es el papel significativo de este tipo de producción en la difusión de los diferentes discursos sobre la nación. El enfoque propuesto tiene la base teórica de los estudios Joel Zito Araújo (2004), Linda Hutcheon (1991), Sandra Pesavento (2008), Paul Ricoeur (1997) y Roger Chartier (1990). Mientras que la telenovela ocupa un lugar prominente como un producto cultural en Brasil, Lado a Lado propagación contribuciones importantes en la historia de negro después de la abolición.

Palabras clave: Lado a Lado. La ficción y la historia. Representación Negro.

\section{INTRODUÇÃO}

O estudo da relação entre a ficção e a História a partir da telenovela Lado a Lado, veiculada pela Rede Globo de Televisão, tem como objetivo analisar a representação do negro nesse produto cultural, levando em consideração a recorrente ausência da temática referente aos afrodescendentes na teledramaturgia nacional.

A telenovela ocupa um lugar de destaque como produto cultural no Brasil. Sua presença cotidiana nos lares de muitos brasileiros faz com que esse gênero de ficção seja contundente, na formação do imaginário nacional, acerca dos mais variados assuntos. A novela em questão, ao engendrar a história das protagonistas - Isabel e Laura -, aborda elementos da História do período de pós-abolição vivido no Brasil, quando transcorrem os fatos. É possível, pois, justificar a relevância desta análise sobre a ficção e a História a partir da representação do negro na telenovela Lado a Lado, devido ao significativo papel desse tipo de produção na difusão de diferentes discursos e, muitas vezes, na mudança de leitura dos telespectadores acerca de determinados temas.

O enfoque proposto por esta reflexão tem como marco teórico os estudos de Joel Zito Araújo (2004), que discute a importância da teledramaturgia no Brasil e analisa o espaço ocupado pelos negros nas telenovelas nacionais, além de Linda Hutcheon (1991), Sandra 
Pesavento (2008) e Paul Ricoeur (1997) que estudam as relações entre a ficção e a História. As contribuições de Roger Chartier (1990) acerca das representações também são referência para este estudo.

\section{A TELENOVELA DESCREVENDO O BRASIL}

Desde 1964, quando a primeira telenovela ${ }^{1}$, organizada da forma como conhecemos hoje, foi ao ar, os brasileiros estão habituados a acompanhar e a se envolver nas tramas dos enredos propostos pela televisão. Assim, assistir a uma telenovela tem feito parte do cotidiano do país há, pelo menos, 50 anos e a relevância desse produto cultural no cenário cultural do Brasil é notório e, por vezes, tem superado outras formas de entretenimento, pois "nessa dimensão territorial tão desigual essa é, muitas vezes, a única forma de lazer possível a milhões de brasileiros" (MALCHER, 2010, p. 87).

Dessa forma, de acordo com Ismael Fernandes (1997), a teledramaturgia alcança o status de "instituição nacional", atuando no campo da cultura popular sem qualquer pretensão erudita.

A telenovela tornou-se uma arte respeitável em suas particularidades. Uma arte popular, brasileira, com vida própria, desenraizada dos conceitos filosóficos e acadêmicos com que tentam interpretá-la. Não há erudição em seus efeitos. Tampouco existe a pretensão dos homens que produzem a telenovela brasileira, em transpor a barreira da arte popular para se embrenhar no restrito e fechado círculo da intelectualidade (FERNANDES, 1997, p. 21).

Além dessa estreita aproximação com o gosto popular, que facilita a compreensão de suas tramas, a telenovela oferece a seu público a comodidade da "entrega em domicílio". Nesse sentido, os telespectadores abrem as portas de seus lares para que a infinidade de discursos, posturas e concepções, que compõem os enredos dessas narrativas, passem a habitar diariamente suas residências. No Brasil, a condição das telenovelas é tão privilegiada que determinadas obras tornam-se assunto cotidiano, extrapolando o espaço doméstico, alterando a grade de horários do resto da programação de uma emissora ou, ainda, estimulando comportamentos e promovendo a proliferação de jargões próprios de certas personagens.

Se considerarmos que grande parte das telenovelas veiculadas tem como cenário o território brasileiro, seja retratando a atualidade ou determinados períodos do passado, podemos estabelecer que, periodicamente, os brasileiros observam, nas telas da televisão,

\footnotetext{
${ }^{1}$ Telenovela O Direito de Nascer, veiculada pela TV TUPI.
} 
obras de ficção que procuram representar a sua própria identidade. Dessa maneira, a televisão e, especialmente, a teledramaturgia participam ativamente da construção de sentidos e de imagens sobre nós mesmos. Se as composições são inspiradas nos fatos, sujeitos e relações vivenciados no Brasil, logo, não há como desassociar diversos aspectos de suas representações da realidade encontrada em nosso território, seja no passado ou no presente. Sobre isso, é pertinente a afirmação de Michel Maffesoli (2001, p. 81) de que "as tecnologias do imaginário bebem em fontes imaginárias para alimentar imaginários”.

Assim, a ficção seriada brasileira atua como um espelho que reflete e refrata a imagem da nação, embora, também produzam reflexos nessa sociedade. Nessa perspectiva, mesmo que os enredos contenham exageros ou assumam posições cômicas, é inegável o componente de inspiração na realidade, o que, consequentemente, produz um efeito de formação de opiniões e reprodução das imagens apresentadas.

A abrangência discursiva das telenovelas tornou-se tão significativa que percebemos seu alcance ultrapassando os limites da televisão. É quase que automática a referência de elementos ligados aos enredos da teledramaturgia em outros veículos de comunicação como revistas, jornais e publicidade. O interesse da população e o fascínio produzido excedem, inclusive, o período de duração das tramas, pois, comumente, encontramos menções a obras que nem ao menos estrearam ou que já tiveram seus capítulos encerrados.

A Rede Globo, líder de audiência nacional e uma das referências mundiais no gênero, investe muito nas telenovelas e apresenta, de segunda a sexta-feira, em três horários diferentes, obras que causam grande identificação por parte do público brasileiro.

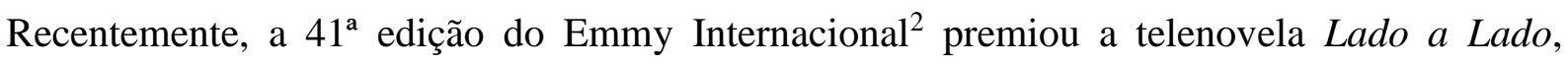
exibida entre setembro de 2012 e março do ano seguinte, como a melhor novela de 2013.

Essa telenovela ${ }^{3}$ contou a história de duas mulheres, Isabel e Laura, pertencentes a grupos sociais distintos que têm suas vidas entrecruzadas e que, além da amizade, dividem experiências e procuram ultrapassar barreiras. Ambas convivem com suas famílias, envolvem-se em romances, mas, sobretudo, vivenciam as dificuldades para transpor o conservadorismo da época. O enredo se passa no Brasil do início do século XX e ganha destaque por apresentar, como pano de fundo da trama o contexto do Rio de Janeiro, que, entre outros aspectos, expõe o cotidiano da primeira geração de negros livres do país e, assim, denuncia mazelas do racismo brasileiro tão pouco referido em nossa sociedade.

\footnotetext{
${ }^{2}$ Prêmio concedido pela Academia Internacional das Artes \& Ciências Televisivas a programas de todo o mundo exibidos através da televisão.

${ }^{3}$ A telenovela Lado a Lado foi escrita por João Ximenes Braga e Cláudia Lage e dirigida por Denis Carvalho e Vinícius Coimbra, tendo sido dividida em 154 capítulos.
} 


\section{REPRESENTANDO A FICÇÃO E A HISTÓRIA}

Brasil, Rio de Janeiro, ano de 1903. Esse é o marco referencial para o princípio da trama apresentada na telenovela Lado a Lado. Desde as imagens iniciais que apresentam cenas da então capital do país, passando pela trilha sonora que posiciona uma música instrumental marcada pela percussão sucedida por um rap, até a cena de um carnaval de rua que marca o início da aparição das personagens, Lado a Lado não deixa dúvidas do que vai narrar. Os contrastes entre as ruas cariocas habitadas por distintos senhores e senhores em trajes sofisticados (espaço onde vive a personagem Laura) e as cenas das camadas populares menos favorecidas se divertindo no carnaval (destaque para a dança protagonizada pela atriz Camila Pitanga, que deu vida à Isabel) apontam para uma narrativa que discutirá, entre outros pontos, as diferenças e as semelhanças entre dois universos sociais. Nas figuras 1 e 2 as protagonistas mencionadas aparecem dialogando com outras personagens dos seus núcleos sociais.

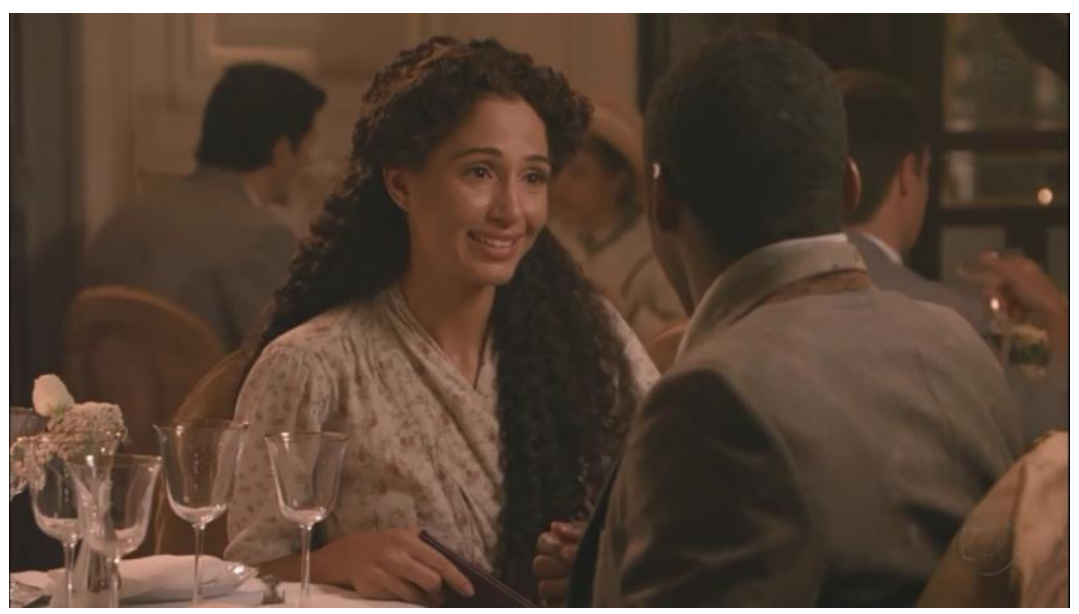

Figura 1 - Isabel

Fonte: Cena da Telenovela Lado a Lado

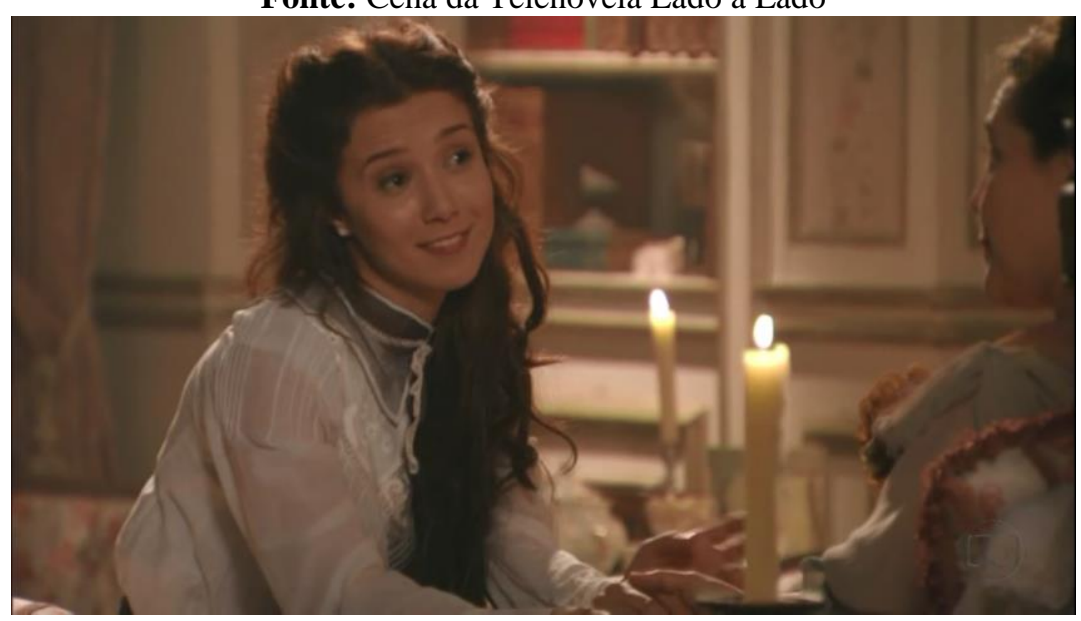

Figura 2 - Laura

Fonte: Cena da Telenovela Lado a Lado 
A escolha por essa abordagem expõe uma realidade pouco representada na teledramaturgia brasileira: a situação do país no período imediatamente posterior à abolição da escravatura. Nesse sentido, a telenovela opta por realizar não apenas a ficcionalização da realidade, mas, sobretudo, uma discussão histórica acerca daquele contexto. E com essa perspectiva, é possível inclinar-se à possibilidade de que o "passado não é mais o que explica o presente, mas este que comanda uma ou várias leituras do passado" (FIGUEIREDO, 2010, p. 89). Em outras palavras, em uma época de políticas afirmativas, cabe ao presente instituir uma revisão do passado, questionando-o e propondo novas leituras sobre ele.

$\mathrm{Na}$ trama, o núcleo de personagens que abriga a trajetória de Isabel é composto por inúmeros atores negros. No enredo, eles, incluindo a protagonista Isabel, são descendentes próximos de escravos que foram libertados pela Lei Áurea, em 1888 (apenas 15 anos antes do início do tempo da narrativa). A presença de uma protagonista negra e a consequente apresentação de um grande núcleo de afrodescendentes não é uma composição comum na teledramaturgia brasileira. O que somos acostumados a presenciar é a ausência de atores negros nas novelas ou, ainda, a sua identidade associada a determinados papéis que, em sua maioria, representam grupos sociais marginalizados, normalmente, carregados de estereótipos.

Essa postura não é percebida apenas na televisão. Pelo contrário, desde a época retratada pela novela Lado a Lado, setores conservadores da sociedade brasileira disseminam pelas áreas culturais, sociais e políticas, aquilo que Joel Zito Araújo (2004) chama de "ideologia do branqueamento", num árduo trabalho que parece objetivar o apagamento da herança africana no Brasil. A ideia de democracia racial estaria, nesse contexto, a serviço dessa ideologia, procurando minimizar, quando não extinguir, as influências negras e o seu papel na composição social brasileira. Dessa forma, anunciando que, no Brasil, todos vivem e convivem, pacífica e igualitariamente, as elites procuraram, ao longo de décadas, garantir seus privilégios e impedir possíveis enfrentamentos por parte dos negros.

Assim, dialogando com o imaginário popular, a teledramaturgia brasileira apresenta fortes resquícios desse posicionamento, negando a diversidade racial brasileira, através da invisibilidade dos negros em suas narrativas, como constata Araújo (2004, p. 109): "nenhuma história levada ao ar nos anos 70, pela Rede Tupi e Rede Globo se propôs a contar os conflitos e os dramas da luta pela ascensão social e econômica da população negra na sociedade brasileira”. Nas décadas seguintes, o panorama apresenta exceções, mas reafirma uma tendência predominante em desvalorizar essa temática na televisão: 
As imagens dominantes no conjunto das telenovelas que foram ao ar no período de 1963 a 1997 revelam a cumplicidade da televisão com a persistência do ideal do branqueamento e com o desejo de euro-norteamericanização dos brasileiros (ARAÚJO, 2004, p. 305).

No entanto, a partir dos anos 90, foram perceptíveis algumas alterações nesse quadro, pelo menos, no que diz respeito à aparição dos negros nas telenovelas. Muitas personagens estiveram fora de representações associadas às camadas desfavorecidas e subalternas e, inclusive, tivemos casos de atores negros protagonizando essas narrativas ocupando, também, papéis de classe média ou alta, com destaque econômico, intelectual e social. Algumas obras apresentaram, de forma inovadora, a temática do racismo em suas tramas. Em 1995, por exemplo, a telenovela A Próxima Vítima apresentou uma família negra de classe média que possuía papéis, de certa forma, expressivos na narrativa. Em 1997, a telenovela Por Amor abordou o preconceito racial de maneira um pouco mais objetiva. Nos anos 2000 foi possível presenciar pelo menos três telenovelas da Rede Globo de Televisão que continham protagonistas negras, como nas novelas Da Cor do Pecado (2004), Viver a Vida (2009) e Cama de Gato (2009).

Em 2013, a novela Lado a Lado, por apresentar um período histórico em que a marginalização e a discriminação oprimia quase que a totalidade dos negros, retomou a representação dos afrodescendentes em um caráter de exclusão social. Entretanto, o que a trama traz de novidade é a abordagem que colocou os negros como protagonistas e que discutiu, sem melindres, a questão do racismo no Brasil, além de explicitar inúmeras formas de participação do negro no cenário cultural, social e político do país.

Considerando que "história e a ficção sempre foram conhecidas como gêneros permeáveis" (HUTCHEON, 1991, p. 143), a telenovela Lado a Lado explora de maneira bastante ousada essa aproximação, visto que destaca, ao longo de toda a narrativa, as possibilidades de envolvimento das personagens em fatos históricos conhecidos. E nesse sentido, afirma um papel ativo e protagonista das personagens negras na construção e nos desdobramentos desses contextos.

Como exemplo dessa perspectiva, é possível elencar o envolvimento das personagens fictícias em momentos históricos, tais como: a demolição dos cortiços no Rio de Janeiro e a posterior transferência dos seus moradores para espaços compostos por habitações precárias que futuramente seriam chamados de favelas; a polêmica relacionada à vacinação contra a 
varíola, ocasionando a chamada Revolta da Vacina ${ }^{4}$; a indignação dos marujos negros contra os maus tratos sofridos na Marinha Brasileira, dando origem à Revolta da Chibata ${ }^{5}$; a ascensão internacional do samba e o incipiente consentimento da capoeira e do candomblé como elementos culturais passíveis de aceitação pública no Brasil. A figura 3 ilustra o Morro da Providência, onde a personagem do ator Lázaro Ramos (Zé Maria) vive durante grande parte da trama junto com as demais personagens que formam o núcleo próximo à Isabel. $\mathrm{O}$ Morro da Providência, simboliza, no enredo, o início da formação das favelas no Rio de Janeiro e reúne a população que, por pressão do governo, deixa os cortiços e fica quase sem perspectivas de vida. É no morro que essas pessoas se agrupam e passam a reconstruir suas trajetórias.

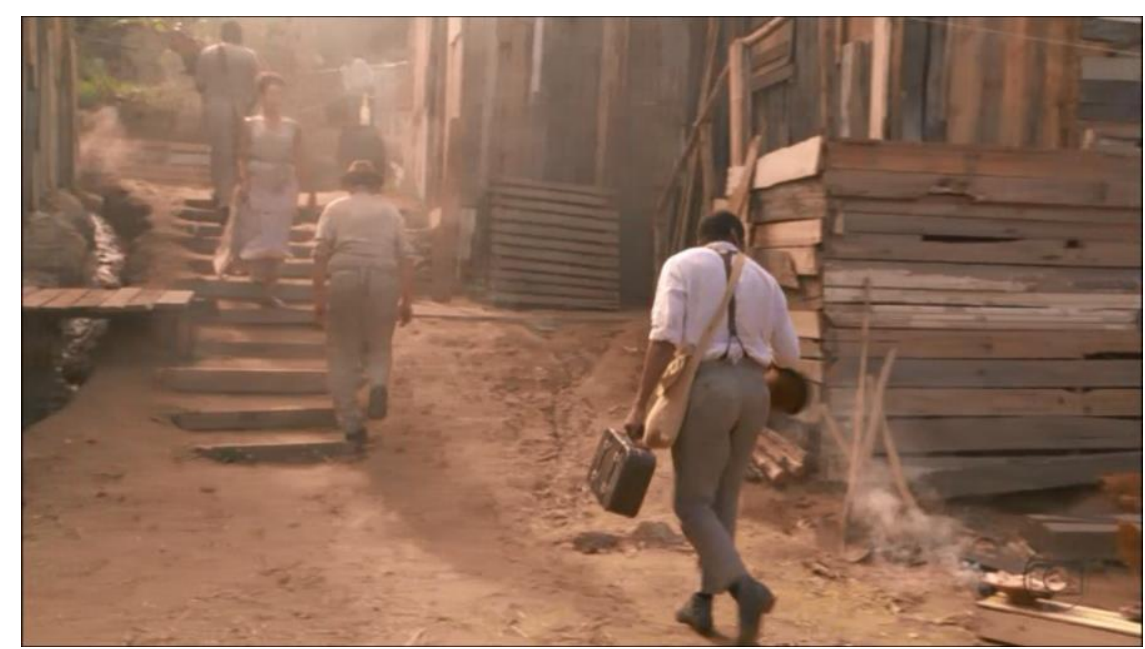

Figura 3 - Morro da Providência

Fonte: Cena da Telenovela Lado a Lado

Esses e outros momentos históricos descritos nessa narrativa ficcional ressaltam a linha tênue que separa a ficção e a História e, sobretudo, valorizam o papel do negro na trajetória de construção da sociedade brasileira, destacando suas lutas, suas dificuldades e, especialmente, sua cultura. Nesse sentido, a verossimilhança "passa a ocupar o lugar da veracidade, trazendo consigo a delicada questão da ficção, a aproximar a história da literatura" (PESAVENTO, 2008, p. 181), neste caso, da telenovela. Assim, a novela preocupa-se menos em retratar o real e mais em inspirar-se na realidade para criar uma

\footnotetext{
${ }^{4}$ Manifestação popular ocorrida em 1904, no Rio de Janeiro, desencadeada pela campanha federal de vacinação obrigatória contra a varíola. Essa decisão do governo causou pânico nas classes populares, pois, diante da ausência de explicação das razões da vacina, as pessoas passaram a pensar que haveria um extermínio coletivo.

${ }^{5}$ Nome popular que recebeu a revolta dos marinheiros de 1910 que denunciaram os castigos físicos recebidos na Marinha Nacional, especialmente, aplicados contra os marinheiros negros. A revolta foi liderada pelo marinheiro João Cândido Felisberto, conhecido como "Almirante Negro".
} 
narrativa ficcional capaz de atrair e convencer pela verossimilhança das abordagens tratadas. Essa questão identifica a narrativa com “o provável, no sentido do que poderia ocorrer" (RICOEUR, 1997, p. 331).

Dessa forma, examinando a ideia proposta por Paul Ricoeur (1997, p. 329), em que "a ficção é quase histórica tanto quanto a história é quase fictícia”, percebe-se, na obra de teledramaturgia, diversos componentes em que a ficção, a História e a representação do negro fornecem elementos para que se possa considerar a telenovela Lado a Lado como uma espécie de metaficção historiográfica. Essa associação pode ser justificada com base na tendência, explicitada na narrativa, em problematizar o conhecimento histórico e questionar o acesso que temos ao passado, abordando mais a verossimilhança do que a busca por verdades absolutas.

Assim, a referida obra de ficção está inserida na pós-modernidade e "sugere que reescrever ou reapresentar o passado na ficção e na história é - em ambos os casos - revelá-lo ao presente, impedindo de ser conclusivo e teleológico" (HUTCHEON, 1991, p. 147). Em Lado a Lado, constantemente as versões e as abordagens históricas são problematizadas e a leitura que se faz do passado, a partir dessa perspectiva, permite ampliar as concepções e refletir sobre os desdobramentos sociais, culturais e políticos do país. Dessa maneira, "o que muda não é o acontecimento em si, mas a sua forma de interpretá-lo, fazendo da história um contínuo retecer de tramas e respostas" (PESAVENTO, 2008, p. 184).

A questão da discriminação racial e econômica é outro aspecto relevante da obra que, contextualizada pelos eventos históricos que permeiam a narrativa, é abordada de forma corajosa e explícita, evitando representações caricaturais ou diálogos que procurem amenizar a situação. Logo no capítulo inicial, que destacou o carnaval no Rio de Janeiro do início do século, a postura da população branca em relação aos negros aponta que, durante a festa, a miscigenação brasileira é aceita e, até certo ponto, valorizada. Entretanto, quando os festejos encerram, assume uma postura preconceituosa e a exclusão social volta a ser preponderante.

Expressões como: "más companhias", "música de negros" e "o tal do samba” foram proferidas pela vilã Constância, interpretada por Patrícia Pillar, já nas primeiras cenas da novela. É dela também a frase que classifica o samba como uma "batucada de africanos, de macumbeiros", duvidando de que o ritmo tenha "qualquer importância para o Brasil". Esse ataque a um elemento cultural do país demonstra que aquilo que, hoje, representa a nação, já foi motivo de discriminação e significava um componente que separava as classes sociais. Posição semelhante ao samba ocupava também a capoeira e o candomblé. Na narrativa, esses e outros elementos culturais, herdados dos africanos escravizados no Brasil, passam por um árduo caminho de afirmação e respeito perante a sociedade branca do país. E, por vezes, são 
questionados pelos próprios afrodescendentes que, devido à discriminação, passam a colocar em xeque a importância dessas manifestações para o cenário social brasileiro.

Lado a Lado enfatiza uma composição social diversa em relação à comunidade negra presente na narrativa. Embora apresente personagens comumente associados a esse grupo étnico, a novela desenvolve inúmeras circunstâncias que auxiliam na compreensão da multiplicidade de representações possíveis em relação ao negro brasileiro. Dessa forma, além da mulata sensual personificada em Berenice (Sheron Menezzes) ou do malandro capoeirista vivido por Caniço (Marcello Melo Jr.), a novela destaca ainda outras formas de atuação dos atores negros.

O protagonista negro Zé Maria, ou Zé Navalha, como também é chamado (representado por Lázaro Ramos), reúne qualificações que vão além da habilidade com a capoeira. Ele tem bons sentimentos, é incorruptível, trabalhador, eloquente e possui um grau elevado de conscientização política e vontade de lutar por justiça social. É ele que, ao longo de toda a narrativa, atua em várias situações históricas e ficcionais, sendo inclusive considerado um herói. São exemplos dessa postura, o seu envolvimento nas revoltas mencionadas anteriormente, na tentativa de impedir a demolição dos cortiços, além das habituais formas de defesa dos seus amigos e vizinhos, atuando tanto com o enfrentamento físico como verbal. Após viajar pelo mundo como marinheiro, Zé Maria assume a função de contador no jornal, reorganizando a administração da empresa, a qual, anteriormente, estava sempre prestes a falir. O jornal passa, então, a dar lucro, e consequentemente Zé Maria se consagra no ofício aprendido na Marinha. Na figura 4, Zé Maria já ocupa o ofício de contador e consegue, por meio dessa atividade, transformar a sua realidade social.

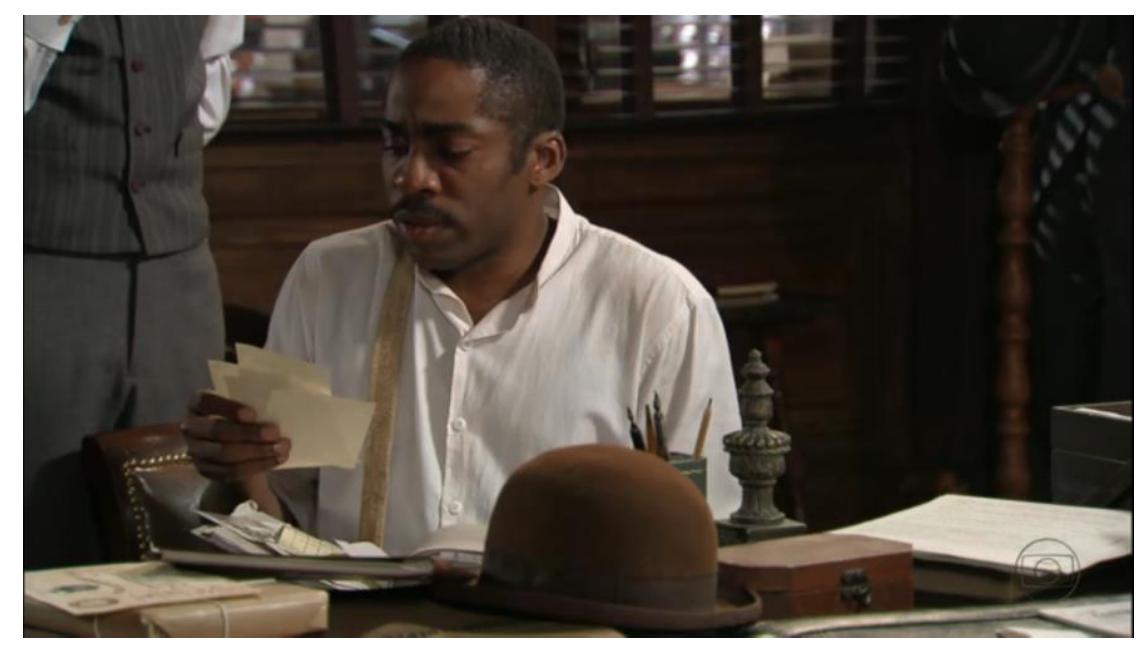

Figura 4 - Zé Maria como contador

Fonte: Cena da Telenovela Lado a Lado 
A protagonista Isabel (vivida pela atriz Camila Pitanga) aparece como uma moça humilde, honesta, romântica e preocupada com o pai, que trabalha na casa de uma senhora francesa. Por isso, aprende a ler e a escrever além de ser ensinada a falar francês. Isabel tem inúmeras qualidades e acaba sobressaindo-se através do samba. É com a dança que ela vai para a Europa, fica famosa e volta ao Brasil em ótimas condições de vida, que lhe dão a possibilidade de comprar um teatro e de melhorar a vida daqueles a quem ama, inclusive, Laura, a filha da baronesa. Na figura 5, Isabel é apresentada de maneira bem sucedida. Ocupando uma mansão no Rio de Janeiro, longe do Morro da Providência, a personagem possui criadas e inverte a lógica social a que estava fadada morando na favela. Curiosamente, em relação à época, Isabel, mulata, é servida por uma empregada doméstica branca, situação pouco comum para os padrões daquele momento histórico.

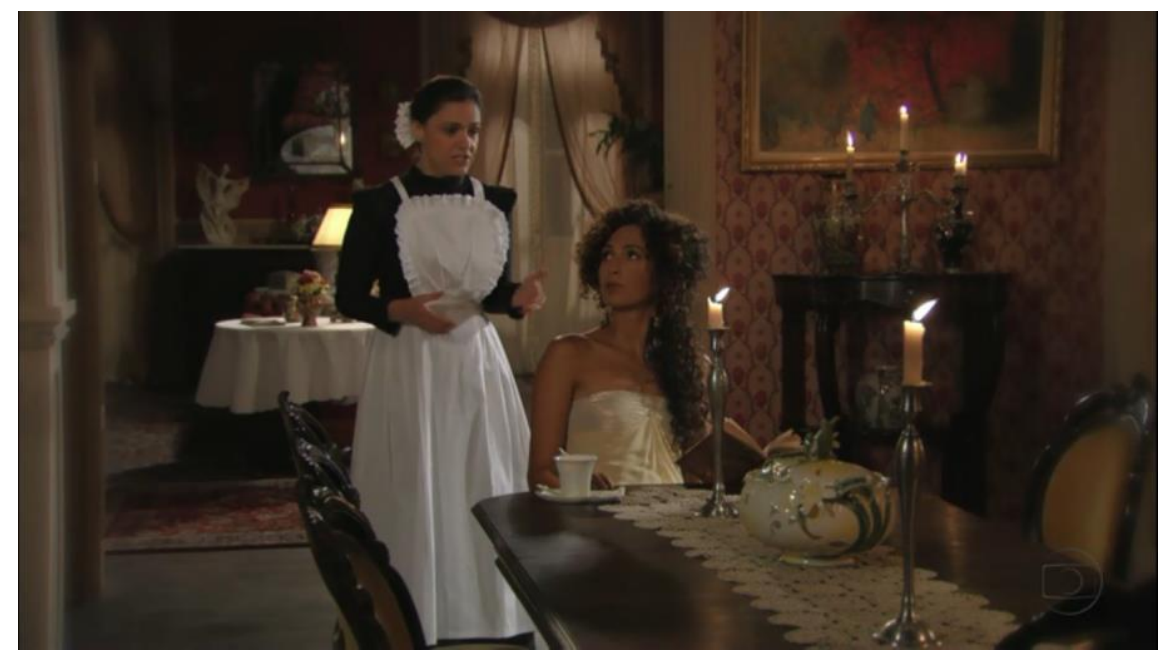

Figura 5 - Isabel em sua mansão

Fonte: Cena da Telenovela Lado a Lado

O pai da moça, Seu Afonso, criara a filha sozinho, em virtude da morte da esposa. Foi dele que Isabel herdou suas principais virtudes. Seu Afonso é muito severo com a filha quando descobre sua gravidez e, mais tarde, quando Isabel fica famosa fora do país através do samba. Ele é um vizinho respeitado e devido a profissão de barbeiro consegue manter uma vida pobre, mas digna, sem esquecer do seu recente passado de escravo.

Tia Jurema vive no morro e tem um carinho muito especial por Isabel e Zé Maria. Ela é uma das referências na comunidade, procurada pela habilidade em jogar búzios. Animada, costuma liderar as festas no morro e tem sempre palavras de conforto e incentivo a quem a procura. É ela que, por meio do jogo de búzios, informa Isabel de que o filho desta está vivo (fora raptado e criado no morro sob a tutela da baronesa), contrariamente ao que se acreditava. Esse episódio confere credibilidade ao jogo, constituindo uma avaliação positiva dessa prática 
de matriz africana. Na figura 6, a personagem Jurema aparece jogando búzios para Isabel. Essa personagem protagoniza uma passagem bastante curiosa na trama quando, devido a suas habilidades com o jogo, é considerada uma criminosa e acaba sendo presa. No enredo, a comunidade do Morro da Providência e outros simpatizantes e amigos de Tia Jurema reúnemse para protestar em frente à cadeia a fim de que a decisão policial seja revogada. Nesta situação, fica clara a manifestação da trama em relação a demonstrar a diversidade cultural e representar, de maneira objetiva, as formas de exclusão e preconceito presentes na sociedade brasileira do início do século.

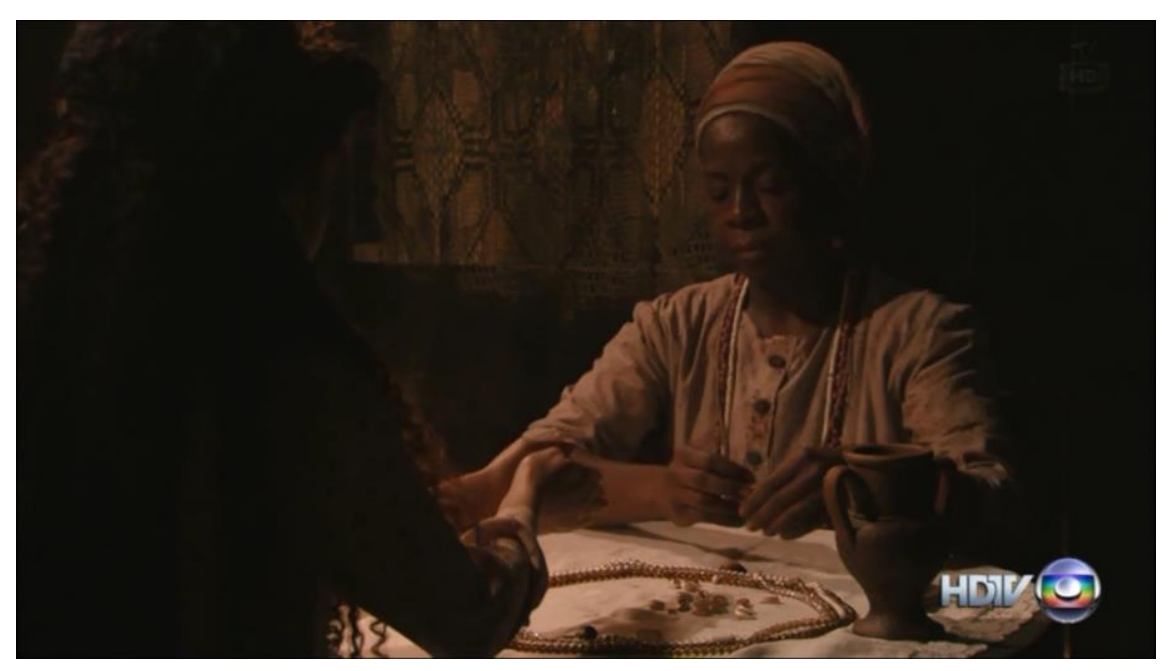

Figura 6 - Tia Jurema jogando búzios

Fonte: Cena da Telenovela Lado a Lado

Essas e outras personagens corroboram a afirmação de que Lado a Lado apresentou representações do negro diversas daquilo que repetidamente é relacionado a esse grupo social, especialmente quando o contexto histórico está associado ao período pós-abolição. Em relação a essa época, normalmente as representações acabam por destacar o papel marginalizado dos negros, silenciando o papel atuante desse grupo étnico na dinâmica social e histórica do Brasil. João Carlos Rodrigues (2001) destaca, em sua obra, a dificuldade da ascensão do negro na sociedade através da sua presença em esferas sociais significativas. No entanto, Lado a Lado exibe uma reavaliação dessa postura e coloca em discussão a presença e o desempenho fundamental do negro na trajetória de diversos eventos nacionais.

São comuns, ao longo da narrativa, algumas frases impactantes, vindas dessas personagens, que revelam o posicionamento crítico presente nessa telenovela acerca da situação do negro no Brasil e que propõe leituras capazes de compreender e dar maior importância a essa presença e atuação no país. São da personagem Isabel frases como: 
“Achavam que, por eu ser negra, essa era a minha única opção de vida" ou "É como se essa vitória pertencesse a cada um do morro”. Chico, o amigo marinheiro de Zé Maria, foi menos esperançoso e alguns momentos: "Libertaram os negros, mas colocaram nossa cultura na cadeira” ou "O mar é um bom caixão para quem já morreu em vida”. Por sua vez, Zé Maria fez outros tantos discursos politizados: "Capoeira não é coisa de marginal, é coisa de brasileiro"; "A gente pode desistir, que é mais fácil, ou lutar”. Esses são alguns enunciados que compõem a obra televisiva Lado a Lado e que ajudam a posicioná-la como um produto de destaque no cenário cultural brasileiro.

A respeito das manifestações culturais herdadas dos negros escravizados no Brasil, Lado a Lado assume uma postura de enfrentamento contra aqueles que discriminam os elementos culturais característicos dos afrodescendentes no período retratado. São recorrentes, na novela, os discursos e as construções de imagens que fazem a defesa, por exemplo, da capoeira como forma de proteção, mas principalmente como elemento capaz de ensinar disciplina, lealdade e valorização da cultura. Ou, ainda, a importância do samba como componente unificador de um povo e conforto para as mazelas pelas quais os moradores do morro passavam. A culinária afro-brasileira também tem destaque na trama e aponta para seu caráter diferencial e reconhecido internacionalmente. A novela menciona também, entre outros aspectos, a defesa ao candomblé e demais manifestações características dos afrodescendentes, distanciando-se de uma abordagem que as rotule como exóticas.

Dessa maneira, ponderando que "a ficção 'é um discurso que informa o real, mas não pretende nem representá-lo, nem fazer acreditá-lo', enquanto a história evidentemente almeja dar uma representação adequada da realidade que existiu e não existe mais" (CHARTIER, 2008, p. 170), a telenovela Lado a Lado, como manifestação cultural desse tempo e ao se aventurar pelos caminhos que separam e que ligam a ficção e a História, retratando, especialmente, o período em que o negro brasileiro estava recentemente livre, aproxima-se do que Pesavento chama de conhecimento sensível que opera "em múltiplos tempos, múltiplas leituras do real, múltiplas maneiras de explicar e traduzir o mundo em palavras" (2008, p. 186). É a busca pelo conhecimento histórico através de relações sociais que, mesmo sendo ficcionais, exploram elementos muito significativos da construção social do Brasil.

Obras dessa natureza têm o importante papel de minimizar equívocos históricos que, segundo Kabengele Munanga e Nilma Gomes (2006) criaram uma visão negativa do negro, associando-o à criminalidade, à pobreza ou à sujeira, impedindo o conhecimento sobre seus processos de luta e suas formas de organização. Lado a Lado contribui, assim, para a disseminação das inúmeras formas de resistência (físicas, mas especialmente culturais) 
empreendidas pelos negros, mesmo após a abolição, período em que esse grupo social precisou, mais do que nunca, resistir às diferentes formas de discriminação e afirmar, como faz até hoje, o seu espaço na sociedade brasileira.

\section{CONSIDERAÇÕES}

Na telenovela Lado a Lado, a História e a ficção não só permitem a reflexão sobre um tempo passado, mas, sobretudo, lançam algumas indagações acerca da atualidade, especialmente no que se refere à situação dos negros hoje e a importância de discutir e apresentar narrativas como essa, a fim de possibilitar maior visibilidade à temática e de valorizar as inúmeras contribuições dos negros ao panorama social, cultural e político do Brasil. Assim, o "entrecruzamento entre a história e a ficção na refiguração do tempo, se baseia em última análise, nessa sobreposição recíproca, quando o momento quase histórico da ficção troca de lugar com o momento quase fictício da história” (RICOEUR, 1997, p. 332). Dessa forma, a História empresta seu contexto para a ficção e, por sua vez, a narrativa ficcional presta um importante serviço à História.

Por conseguinte, com o alcance midiático que tem uma telenovela, as abordagens realizadas em Lado a Lado contribuem para a aproximação dos brasileiros com uma temática, ao mesmo tempo, rica e desconhecida de muitos que vivem no país. Ao contrário do que algumas produções costumam priorizar, essa telenovela se destaca pelo respeito às diferenças e, principalmente, pela criação de representações do negro que contemplam, ao menos, parte da diversidade característica desse grupo, procurando fugir dos arquétipos comuns e ampliando as possibilidades de discussão.

\section{REFERÊNCIAS}

ARAÚJO, Joel Zito. A negação do Brasil: o negro na telenovela brasileira. Senac, 2004.

CHARTIER, Roger. A história: a leitura do tempo. In: SCÜLLER, Fernando; AXT, Günter; Silva, Juremir Machado da. Fronteiras do pensamento: retratos de um mundo complexo. São Leopoldo: Editora UNISINOS, p. 163-178, 2008.

FERNANDES, Ismael. Memória da telenovela brasileira. São Paulo: Brasiliense, 1997.

FIGUEIREDO, V. L. F. Encenação da realidade: fim ou apogeu da ficção (p. 83-99). In: letras, 2010 .

Narrativas migrantes: literatura, roteiro e cinema. Rio de Janeiro: Ed. PUCRio: 7 
HUTCHEON, L. Poética do pós-modernismo. História, teoria, ficção. Trad. Ricardo Cruz. Rio de Janeiro: Imago, 1991.

LADO a Lado. Novela de João Ximenes Braga e Claudia Lage. Telenovela. Rede Globo de Televisão. Setembro/2012 até março/2013.

LADO a Lado. Site oficial da novela. Globo Comunicações e Participações S. A. Disponível em <http://gshow.globo.com/novelas/lado-a-lado/index.html.> Acesso em 27 de junho de 2014.

MAFFESOLI, Michel. O imaginário é uma realidade. In: Revista FAMECOS. Porto Alegre, $\mathrm{n}^{\circ} 15,2001$. Disponível em

<http://revistas.univerciencia.org/index.php/famecos/article/viewFile/285/217> Acesso em 27 de junho de 2014.

MALCHER, Maria Ataíde. Teledramaturgia: agente estratégico na construção da TV aberta brasileira. São Paulo: Intercom, 2010.

MUNANGA, Kabengele; GOMES, Nilma Lino. O negro no Brasil de hoje. Global Editora, 2006.

PESAVENTO, Sandra J. O mundo da imagem: território da história cultural. In:

Narrativas, imagens e práticas sociais: percursos em historia cultural. Porto Alegre: Asterisco, p. 99-122, 2008.

Fronteiras da história: uma leitura sensível do tempo. In: SCÜLLER, Fernando; AXT, Günter; Silva, Juremir Machado da. Fronteiras do pensamento: retratos de um mundo complexo. São Leopoldo: Editora UNISINOS, p. 179-190, 2008.

RICOEUR, Paul. O entrecruzamento da História e da ficção. In: Tempo e narrativa. Tomo III. Campinas: Papirus, 1997.

RODRIGUES, João Carlos. O negro brasileiro e o cinema. Rio de Janeiro: Pallas, 2001.

SKIDMORE, Thomas E. Preto no branco: raça e nacionalidade no pensamento brasileiro. Rio de Janeiro: Paz e Terra, 1976.

Original recebido em: 25/04/2015

Aceito para publicação em: 03/12/2015

Marinês Andrea Kunz

Possui graduação em Letras Português-Alemão pela UNISINOS (1994), mestrado em Ciências da Comunicação pela UNISINOS (1998) e doutorado em Linguística e Letras pela PUC-RS (2004). Atualmente, é professora titular da Universidade Feevale, onde atua no

Curso de Letras, bem como no Mestrado em Processos e Manifestações Culturais e no 
Mestrado de Indústria Criativa. Coordena o Mestrado Profissional em Letras. É autora do livro Mosaico Discursivo: a representação de Jacobina Maurer em textos históricos, literários e fílmicos, além de capítulos de livros e de artigos. Tem experiência na área de Letras, com ênfase em Literatura, Semiótica, Cinema, atuando principalmente nos seguintes temas: literatura, narrativa, leitura, cinema e ensino.

Magna Lima Magalhães

Doutorado pela Universidade do Vale do Rio dos Sinos (2010). Atualmente é professora da Universidade Feevale, no Mestrado em Processos e Manifestações Culturais e do curso de História. Líder do grupo de pesquisa Cultura e Memória da Comunidade e coordenadora do

Centro de Documentação e Memória-Feevale. Tem experiência na área de História, com ênfase em MULTIDISCIPLINAR, atuando principalmente no seguinte tema: memória, história, identidade e associativismo negro. É autora de artigos que discutem a presença negra no Vale dos Sinos/RS entre os quais o Associativismo e sociabilidade negra em Novo

Hamburgo-RS

Cláudia Santos Duarte

Possui graduação em História, pela Universidade do Vale do Rio dos Sinos - UNISINOS (2006), Especialização em História, Comunicação e Memória do Brasil Contemporâneo (2009) e Mestrado em Processos e Manifestações Culturais (2015) - ênfase interdisciplinar em História, Literatura e Comunicação, ambos pela Universidade Feevale. Atualmente é Tutora do Núcleo de Tutorias EaD da Universidade Feevale. Tem experiência docente na educação básica com a disciplina de História. É autora de artigos que discutem representações sociais, narrativas audiovisuais e o negro na sociedade brasileira. 